\title{
System identification of the crab cardiac neuromuscular transform by a new method
}

\author{
Estee Stern*1, Keyla García-Crescioni², Mark W Miller ${ }^{2}$, Charles S Peskin ${ }^{3}$ and \\ Vladimir Brezina ${ }^{1}$
}

\author{
Address: ${ }^{1}$ Department of Neuroscience, Mount Sinai School of Medicine, New York, NY, USA, 2Institute of Neurobiology, University of Puerto \\ Rico Medical Sciences Campus, San Juan, PR, USA and ${ }^{3}$ Courant Institute of Mathematical Sciences and Center for Neural Science, New York \\ University, New York, NY, USA \\ Email: Estee Stern* - estee.stern@mssm.edu \\ * Corresponding author
}

from Seventeenth Annual Computational Neuroscience Meeting: CNS*2008

Portland, OR, USA. 19-24 July 2008

Published: II July 2008

BMC Neuroscience 2008, 9(Suppl I):P25 doi:10.1 I86/I47I-2202-9-SI-P25

This abstract is available from: http://www.biomedcentral.com/I47I-2202/9/SI/P25

(c) 2008 Stern et al; licensee BioMed Central Ltd.

The neuromuscular transform (NMT) is the transform of the motor neuron spike train to the waveform of muscle contraction [1]. The NMT is often challenging to understand and model predictively. Each spike elicits an elementary contraction response, but the spike train can be of arbitrary temporal complexity and each elementary response is modified by the previous history of the activity. Furthermore, in slowly contracting muscles the elementary responses summate and fuse and cannot be seen in isolation. Ideally, we would like to characterize the NMT in terms of a small number of functions - the elementary response kernel and additional functions that describe the dependence on previous history - that will predict the response to any arbitrary spike train. Here, using a "decoding" method that we have developed [2], we have characterized in this manner the NMT of the neurogenic heart of the blue crab, Callinectes sapidus. As data, we recorded the heart muscle contractions elicited by random Poisson motor neuron spike trains (Fig. 1A). From these data, the method extracted three functions whose combination, according to a simple model (Fig. 1B), defined the contraction response: $K$, the elementary contraction kernel; $H$, a history kernel; and $F$, a static nonlinearity (Fig. 1C). $H$ was negative immediately after each spike and then, peaking after several seconds, positive. To test the hypothesis that this shape reflected plasticity at the cardiac neuromuscular junctions that mediate the NMT, we recorded, in response to similar random spike trains, the underlying EJPs (not shown). When decoded, these yielded essentially the same $H$, confirming its synaptic, and probably presynaptic, origin. The negative phase can be interpreted as depression, and the positive phase as facilitation, of potential transmitter release after each spike. The shape of $H$ has interesting implications for the case of the endogenous spike pattern where the spikes are fired in bursts several seconds apart. Each spike inhibits the response to the subsequent spikes in the same burst, and the entire burst would produce little contraction were it not preceded, by an interval well matched to the positive phase of $H$, by the previous burst. Thus at the natural frequency of the cardiac rhythm each burst not only produces its own contraction, but enables that of the next burst. We are now examining how the functions of the NMT are altered by endogenous neuromodulators of the crab cardiac system [3]. 

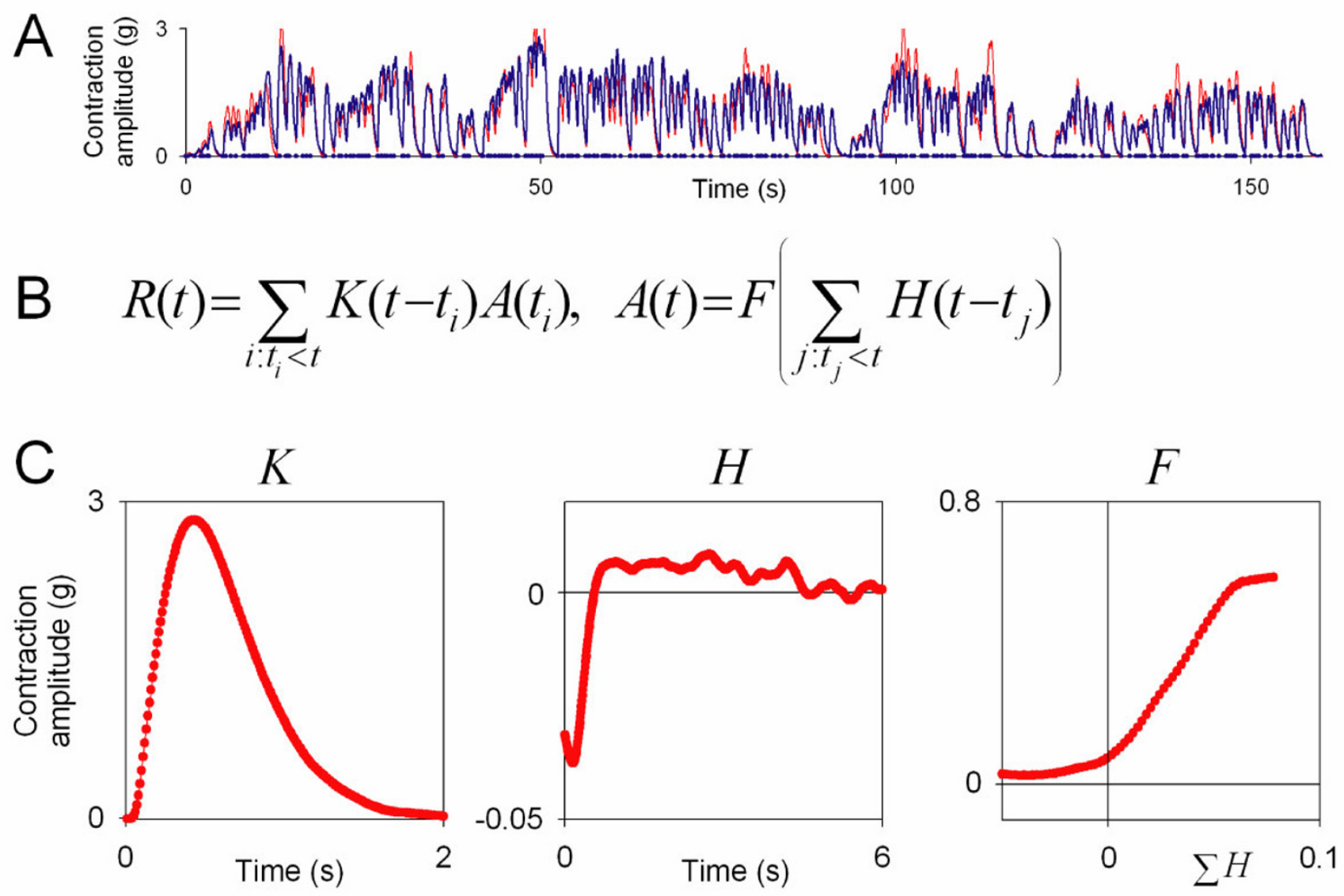

Figure I

Decoding of the crab cardiac NMT. A: representative recording of contraction amplitude (muscle tension) of the heart muscle (blue curve) in response to a train of 295 random motor neuron spikes (blue dots along the baseline) generated by a Poisson process with a nominal rate of $2 \mathrm{~Hz}$, and the contraction estimated by the decoding method (red curve). B: the decoding model. $t=$ time; $t_{i}, t_{j}=$ time of spike $i, j ; R=$ overall contraction response waveform; $K=$ elementary contraction kernel; $A=$ factor scaling the amplitude of $K$ at each spike; $H=$ elementary history kernel; $F=$ static nonlinear function. $C: K, H$, and $F$ decoded from the dataset in $A$.

\section{Acknowledgements}

Supported by NS4I497, GM08224.

\section{References}

I. Brezina V, Orekhova IV, Weiss KR: The neuromuscular transform: the dynamic, nonlinear link between motor neuron firing patterns and muscle contraction in rhythmic behaviors. J Neurophysiol 2000, 83:207-23I.

2. Stern E, Fort TJ, Miller MW, Peskin CS, Brezina V: Decoding neurophysiological responses to arbitrary spike trains. Soc Neurosci Abstr 2006, 49 I.7:

3. Stern E, Fort TJ, Miller MW, Peskin CS, Brezina V: Decoding modulation of the neuromuscular transform. Neurocomputing 2007, 70:1753-1758

\begin{tabular}{|} 
Publish with Biomed Central and every \\
scientist can read your work free of charge \\
"BioMed Central will be the most significant development for \\
disseminating the results of biomedical research in our lifetime. " \\
Sir Paul Nurse, Cancer Research UK \\
Your research papers will be: \\
• available free of charge to the entire biomedical community \\
• peer reviewed and published immediately upon acceptance \\
• cited in PubMed and archived on PubMed Central \\
• yours - you keep the copyright \\
Submit your manuscript here: \\
http://www.biomedcentral.com/info/publishing_advasp
\end{tabular}

